\title{
VARIAÇÃO ESPACIAL DA PRECIPITAÇÃO PLUVIAL NA BACIA HIDROGRÁFICA DO RIO ITAPICURU - BA
}

\author{
Telma Lucia Bezerra Alves ${ }^{(a)}$, Greyce Bernardes de Mello Rezende ${ }^{(b)}$ Débora Aparecida da Silva
} Santos ${ }^{(c)}$

(a) Instituto Federal de Alagoas (IFAL), Email: telmaluciax@ @otmail.com

(b) Universidade Federal do Mato Grosso, (UFMT), Email: greycebernardes@ yahoo.com.br

(c) Universidade Federal do Mato Grosso, (UFMT) Email: deboraassantos@ hotmail.com

\section{Eixo: Climatologia em diferentes níveis escalares: mudanças e variabilidades}

\begin{abstract}
Resumo
O presente estudo teve como objetivo analisar a variação espacial da precipitação pluvial na Bacia Hidrográfica do Rio Itapicuru. Foram utilizadas séries temporais de precipitação pluvial superiores a trinta anos, para 21 localidades inseridas total ou parcialmente na Bacia Hidrográfica do Rio Itapicuru. Utilizaram-se imagens SRTM Topodata, com resolução de $30 \mathrm{~m}$, para obtenção de mapa hipsométrico e softwares específicos para o processamento dos dados. Os resultados indicam que a distrinuição da precipitação pluvial na bacia é condicionada por fatores geográficos, principalmente o relevo. Os valores anuais mais elevados ocorrem no baixo curso, área litorânea, e na região de altitude mais acentuda. A região interplanáltica do médio curso apresenta baixos valores de precipitação.
\end{abstract}

Palavras chave: chuva; semirárido; relevo.

\section{Introdução}

As constantes variabilidades climáticas do Nordeste brasileiro estão relacionadas, há vários fatores, dentre eles: a posição da Zona de Convergência Intertropical (ZCIT), o fenômeno El Niño - Oscilação Sul (ENOS), oscilações de Temperatura da Superfície do Mar (TSM), os quais são mecanismos interrelacionados que causam variabilidade na precipitação e no clima (NOBRE \& SHUKLA, 1996; MOLION \& BERNARDO, 2002).

O modelo mensal e interanual de distribuição de chuvas no Semiárido brasileiro é extremamente irregular, tanto no tempo quanto no espaço geográfico. Convém ressaltar ainda que a variabilidade da precipitação nessa região está relacionada também ao fato de que nas baixas latitudes, a precipitação é controlada principalmente pela dinâmica dos ventos, nas zonas associadas de convergência e divergência. Essa característica de irregularidade das precipitações demonstra a falta de confiabilidade com as quais determinadas quantidades de precipitação podem ser esperadas.

Em regiões semiáridas, o conhecimento do regime pluvial, que se caracteriza por alto déficit hídrico, é de extrema importância para vários setores da sociedade, tornando-se fundamental conhecer os efeitos dos 

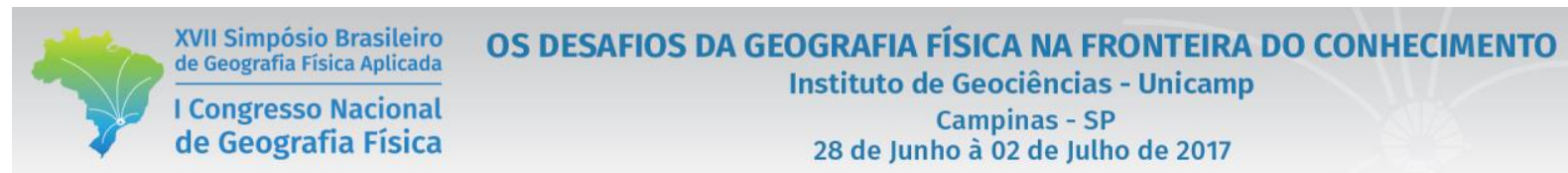

elementos do clima de forma a se obter um gerenciamento e uso racional dos recursos hídricos. A precipitação pluvial e a evapotranspiração potencial são elementos do clima que ocorrem de forma oposta e são expressos na mesma unidade de medida (mm).

A bacia hidrográfica do Rio Itapicuru é muito importante para o desenvolvimento do setor norte do Estado da Bahia, por ser provedora de importantes recursos naturais. Atividades agrícolas e mineração são alguns seguimentos que dependem da disponibilidade de recursos hídricos na região.

Com base no exposto, o objetivo do trabalho é avaliar a variação espacial da precipitação pluvial na bacia hidrográfica do Rio Itapicuru.

\section{Metodologia}

\section{Caracterização da área de estudo}

A bacia hidrográfica do Rio Itapicuru (Figura 1) está localizada na região nordeste (NE) do estado da Bahia, com uma área de $8.664 \mathrm{~km}^{2}(6,60 \%$ do estado), integrando total ou parcialmente a área de 55 municípios.

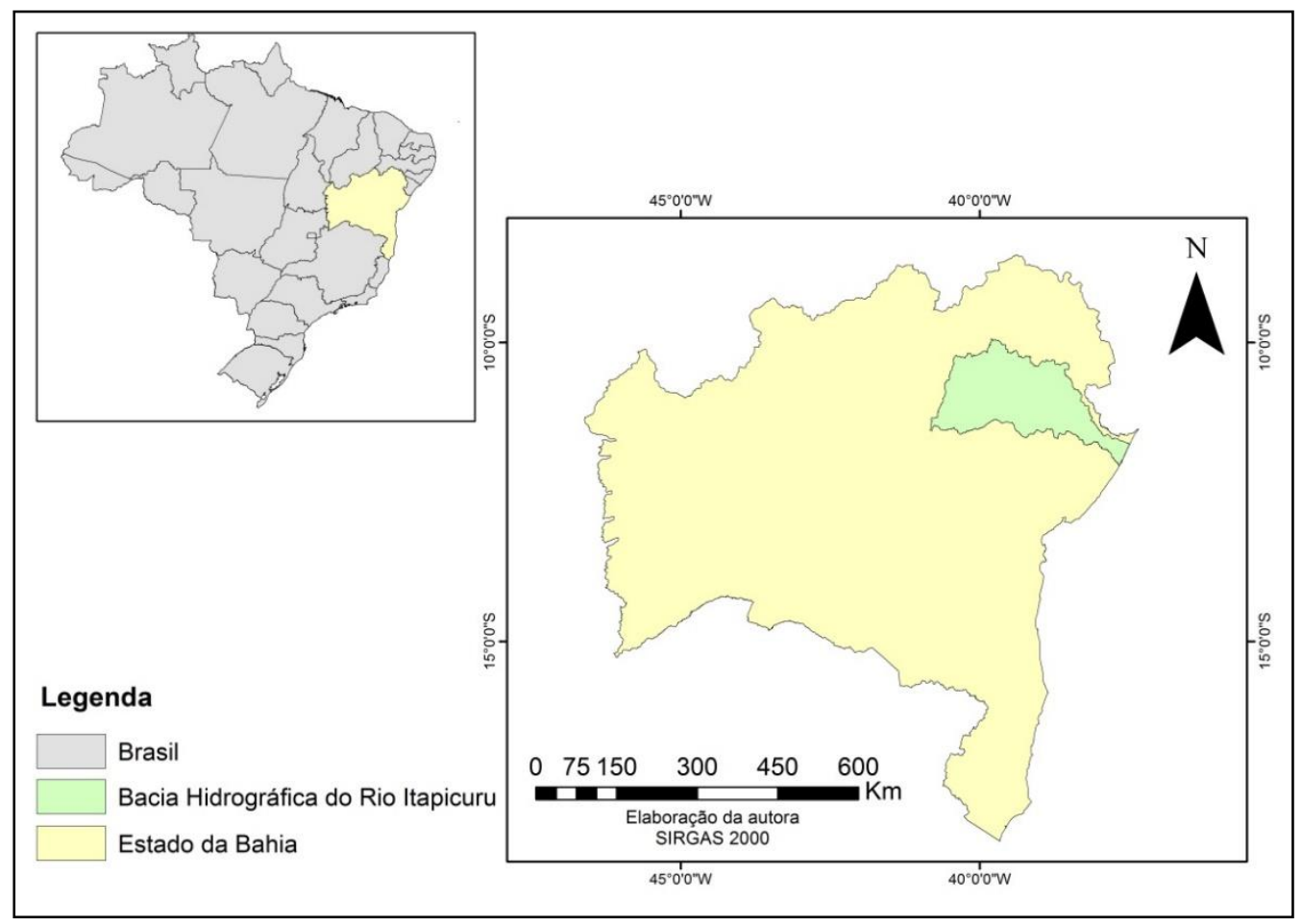

Figura 1 - Localização da Bacia Hidrográfica do Rio Itapicuru na região nordeste (NE) do estado da Bahia.

A bacia apresenta um Clima semiárido em $81 \%$ da área, com chuvas anuais inferiores a $700 \mathrm{~mm}$. No alto curso da bacia hidrográfica, já na Chapada da Diamantina, o clima torna-se mais ameno mudando para o tipo subúmido a seco, com os totais pluviométricos atingindo até $900 \mathrm{~mm}$. No baixo curso da bacia do Rio 


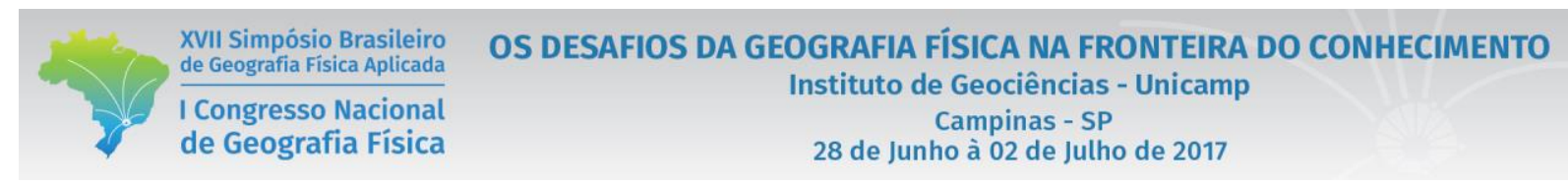

Itapicuru o clima muda para o tipo úmido a subúmido com precipitações variando de 1000 até $1400 \mathrm{~mm}$. O alto curso da bacia está localizado no Pediplano da Chapada da Diamantina, onde ocorrem remanescentes de florestas estacionais e campos rupestres; em sua parte central abrange as depressões periféricas e interplanálticas, e a bacia sedimentar de Tucano, onde predominam as pastagens entremeadas por áreas com vegetação de Caatinga; no seu trecho final, ocorrem espécies florestais secundárias da Mata Atlântica (INEMA, 2017).

\section{Dados climáticos}

Os dados de precipitação pluvial foram obtidos na rede de postos pluviométricos do Instituto Nacional de Meio Ambiente (INEMA), Instituto Nacional de Meteorologia (INMET) e Superintência para o desenvolvimento do Nordeste (SUDENE) para 21 postos (Tabela 1) e disponibilizados pela Unidade Acadêmica de Ciências Atmosféricas (UACA) da Universidade Federal de Campina Grande (UFCG).

Tabela I - Relação das estações pluviométricas da Bacia Hidrográfica do Rio Itapicuru.

\begin{tabular}{llllcc}
\hline $\mathbf{N}^{\circ}$ & \multicolumn{1}{c}{ Estações } & Lat $(\mathbf{S})$ & Long $(\mathbf{W})$ & $\begin{array}{c}\text { Altitude } \\
(\mathbf{m})\end{array}$ & $\begin{array}{c}\text { Período de } \\
\text { observações }\end{array}$ \\
\hline 1 & Conde & $11^{\circ} 52^{\prime} 56^{\prime \prime}$ & $37^{\circ} 57^{\prime} 59^{\prime \prime}$ & 20 & $1944-1989$ \\
\hline 2 & Itapicuru & $11^{\circ} 23^{\prime} 58^{\prime \prime}$ & $38^{\circ} 19^{\prime} 55^{\prime \prime}$ & 153 & $1943-1974$ \\
\hline 3 & Andorinha & $10^{\circ}, 29^{\prime} 12^{\prime \prime}$ & $39^{\circ} 59^{\prime} 11^{\prime \prime}$ & 400 & $1960-1990$ \\
\hline 4 & Tucano & $10^{\circ} 53^{\prime} 00^{\prime \prime}$ & $38^{\circ} 59^{\prime} 12^{\prime \prime}$ & 209 & $1934-1988$ \\
\hline 5 & Queimadas & $11^{\circ} 06^{\prime} 10^{\prime \prime}$ & $39^{\circ} 57^{\prime} 40^{\prime \prime}$ & 273 & $1912-1990$ \\
\hline 6 & Euclides da Cunha & $10^{\circ} 52^{\prime} 50^{\prime \prime}$ & $38^{\circ} 56^{\prime} 10^{\prime \prime}$ & 523 & $1912-1990$ \\
\hline 7 & Senhor do Bonfim & $10^{\circ} 48^{\prime} 86^{\prime \prime}$ & $40^{\circ} 10^{\prime} 50^{\prime \prime}$ & 544 & $1912-1985$ \\
\hline 8 & Jacobina & $11^{\circ} 23^{\prime} 58^{\prime \prime}$ & $40^{\circ} 41^{\prime} 55^{\prime \prime}$ & 460 & $1912-1985$ \\
\hline 9 & Ribeira do Pombal & $10^{\circ} 58^{\prime} 50^{\prime \prime}$ & $38^{\circ} 50^{\prime} 58^{\prime \prime}$ & 228 & $1943-1990$ \\
\hline 10 & Conceição do Coité & $11^{\circ} 51^{\prime} 20^{\prime \prime}$ & $39^{\circ} 23^{\prime} 58^{\prime \prime}$ & 350 & $1936-1990$ \\
\hline 11 & Valente & $11^{\circ} 36^{\prime} 50^{\prime \prime}$ & $39^{\circ} 39^{\prime} 55^{\prime \prime}$ & 350 & $1934-1985$ \\
\hline 12 & Serrolandia & $11^{\circ} 46^{\prime} 58^{\prime \prime}$ & $40^{\circ} 25^{\prime} 59^{\prime \prime}$ & 380 & $1952-1990$ \\
\hline 13 & Miguel calmon & $11^{\circ} 40^{\prime} 50^{\prime \prime}$ & $40^{\circ} 60^{\prime} 55^{\prime \prime}$ & 533 & $1942-1990$ \\
\hline 14 & Esplanada & $11^{\circ} 52^{\prime} 50^{\prime \prime}$ & $37^{\circ} 89^{\prime} 15^{\prime \prime}$ & 181 & $1914-1989$ \\
\hline 15 & Biritinga & $11^{\circ} 39^{\prime} 33^{\prime \prime}$ & $38^{\circ} 83^{\prime} 11^{\prime \prime}$ & 270 & $1960-1990$ \\
\hline 16 & Inhambupe & $11^{\prime} 48^{\prime} 57^{\prime \prime}$ & $38^{\circ} 31^{\prime} 57^{\prime \prime}$ & 180 & $1940-1988$ \\
\hline 17 & Mirangaba & $10^{\circ} 55^{\prime} 20^{\prime \prime}$ & $40^{\circ} 51^{\prime} 10^{\prime \prime}$ & 930 & $1960-1990$ \\
\hline 18 & Campo Formoso & $10^{\circ} 42^{\prime} 50^{\prime \prime}$ & $40^{\circ} 34^{\prime} 55^{\prime \prime}$ & 545 & $1959-1989$ \\
\hline 19 & Pindobaçu & $10^{\circ} 51^{\prime} 15^{\prime \prime}$ & $40^{\circ} 31^{\prime} 38^{\prime \prime}$ & 600 & $1934-1987$ \\
\hline 20 & Jaguarari & $10^{\circ} 29^{\prime} 29^{\prime \prime}$ & $40^{\circ} 16^{\prime} 55^{\prime \prime}$ & 660 & $1934-1990$ \\
\hline & Uaua & $39^{\circ} 04^{\prime} 39^{\prime} \prime 22^{\prime \prime}$ & 439 & $1913-1990$ \\
\hline
\end{tabular}


Para identificar a distribuição espacial da precipitação pluvial foram obtidas isoietas pela técnica geoestatística da krigagem ordinária, do programa Surfer 8.0. Foram utilizadas as médias dos totais anuais de precipitação pluvial, das estações com período de observações igual ou superior a 30 anos.

\section{Dados orbitais}

Foram utilizadas imagens digitais orbitais SRTM - Shuttle Radar Topography Mission. Os dados foram disponibilizados após refinamento e processamento, em formato GeoTiff (.tif), contendo Modelo Digital de Elevação (MDE) refinado, correspondente ao TOPODATA - Banco de dados geomorfométricos do Brasil.

Para elaboração do mapa hipsométrico foram utilizadas 8 folhas para compor o mosaico (nomenclaturas 12S39_ZN, 11S405_ZN, 11S42_ZN, 11S39_ZN, 10S405_ZN, 10S42_ZN, 10S39_ZN e 09S405_ZN), com 30 metros de resolução. Posteriormente o mosaico foi recortado com o shapefile de delimitação da bacia, obtido no site da Agência Nacional de Águas (ANA). Para realização dessas etapas foi utilizado o ArcGIS 10.3.

\section{Resultados e Discussão}

Na Figura 2 observa-se a compartimentação geomorfológica da bacia hidrográfica do Rio Itapicuru, com base nas cotas altimétricas, que variam de $0 \mathrm{~m}$ (baixo curso) a 1.125 metros de altitude (alto curso). Destacam-se ainda, de acordo com o Projeto RADAMBRASIL (1983), os Domínios Morfoestruturais do Escudo Exposto (alto e médio curso) e das Bacias e Coberturas Sedimentares (baixo curso) na área da bacia hidrográfica do Rio Itapicuru. 

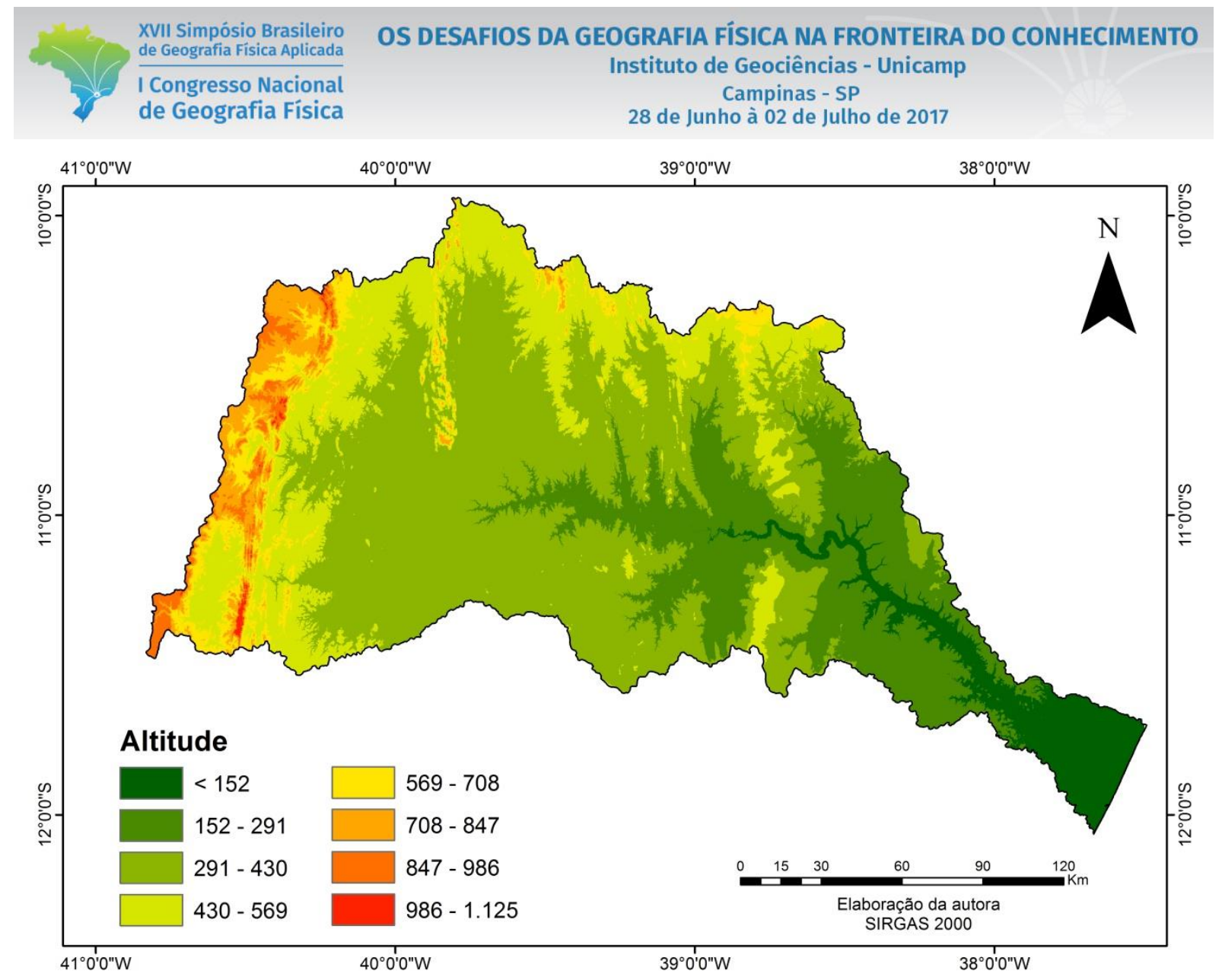

Figura 2 - Mapa hipsométrico da Bacia Hidrográfica do Rio Itapicuru

No Quadro 1 observam-se ainda algumas características geomorfológicas da bacia, compartimentada em trechos:

Quadro 1 - Compartimentação geomorfológica da Bacia Hidrográfica do Rio Itapicuru.

\begin{tabular}{|c|l|c|c|}
\hline Compartimentação & \multicolumn{1}{|c|}{ Domínio Morfoestrutural } & Região & $\begin{array}{c}\text { Unidade } \\
\text { geomorfológica }\end{array}$ \\
\hline & $\begin{array}{l}\text { Domínio Escudo exposto - Engloba } \\
\text { porções emersas da plataforma, } \\
\text { constituídas de antigas cadeias } \\
\text { estabilizadas desde o Pré- }\end{array}$ & $\begin{array}{c}\text { Planaltos } \\
\text { residuais }\end{array}$ & Serra de Jacobina \\
Alto Curso & $\begin{array}{l}\text { Cambriano Inferior. Em } \\
\text { decorrência do tipo de deformação } \\
\text { que sofreram durantes os vários } \\
\text { ciclos tectônicos posteriores foram } \\
\text { atingidas por intensa erosão que } \\
\text { consumiu os complexos de rochas } \\
\text { metafórfico-ígneas. }\end{array}$ & \\
\hline Médio Curso & $\begin{array}{l}\text { Domínio Escudo exposto } \\
\text { Bacias e Coberturas Sedimentares } \\
\text { engloba unidades reconhecidas } \\
\text { pelos topos que acompanham as }\end{array}$ & Bacia Tucano \\
& Jatobá & Tabuleiros do \\
& Itapicuru \\
\hline
\end{tabular}




\begin{tabular}{|l|l|l|}
\hline Baixo Curso & $\begin{array}{l}\text { disposições de camadas e } \\
\text { reelaborados por processo de } \\
\text { aplanamento; constituem tabueiros, } \\
\text { chapadas e mesas, limitados } \\
\text { frequentemente por escarpas } \\
\text { controladas por traços estruturais. A } \\
\text { consistência dos materiais } \\
\text { desenvolve fenômenos de } \\
\text { movimentos de massa. }\end{array} \mid$ \\
\hline
\end{tabular}

A distribuição espacial da precipitação pluvial, bem como seus valores médios, está apresentada na Figura 3. A porção central da bacia apresenta os valores mais baixos de precipitação. Na região do alto curso, próximo ao município de Senhor do Bonfim os valores médios são $950 \mathrm{~mm}$ anuais. Na região do baixo curso, próxima ao litoral, os valores são bem elevados.

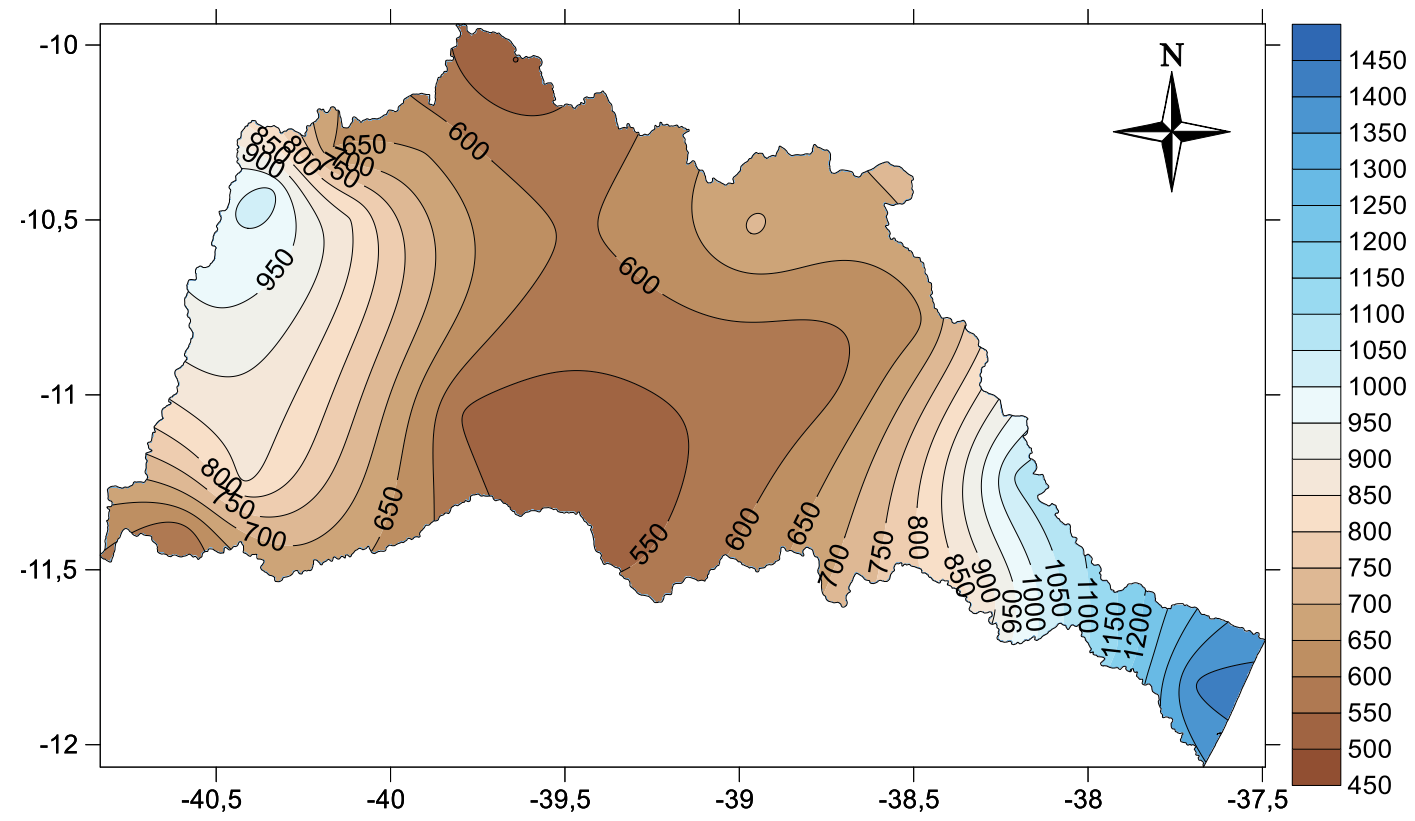

Figura 3 - Distribuição espacial dos valores médios da precipitação pluvial da bacia hidrográfica do Rio Itapicuru.

Nas áreas mais elevadas da bacia, aparecem cotas superiores a $800 \mathrm{~mm}$, que condicionam o surgimento de verdadeiros oásis, os conhecidos "brejos" e "serras" úmidos, , a barlavento dessas barreiras orográficas, em relação ao fluxo dos alísios. A sotavento dessas barreiras aparecem áreas secas, conhecidas como "zonas de sombra de chuvas". Essas barreiras podem ser representadas pela Chapada Diamantina (BRASIL, 1983).

Os níveis mais elevados de precipitação no litoral são explicados pelo efeito da maritimidade, pois os mares e oceanos são fornecedores de água para a troposfera, controlam a distribuição de água e energia entre oceanos e continentes. Assim como pela atuação das Ondas de leste, também conhecidas como 
distúrbios ondulatórios de leste, OL Africanas, são ondas que se formam no campo da pressão atmosférica, ao longo dos alísios, na faixa tropical do globo, deslocando-se de leste para oeste. São capazes de causar precipitações acentuadas ao longo de suas trajetórias. Ocorrem no inverno austral junho, julho e agosto (MACHADO, et al. 2009; MENDONÇA E DANNI-OLIVEIRA, 2007).

A Figura 4 apresenta o comportamento mensal da precipitação pluvial para alguns dos municípios da bacia hidrográfica do Rio Itapicuru. Observa-se que os meses de setembro e outubro apresentam os valores mais baixos, correspondendo à estação seca, que nas regiões interplanálticas semiáridas, tem duração variada, por vezes atingindo nove meses de estiagem.

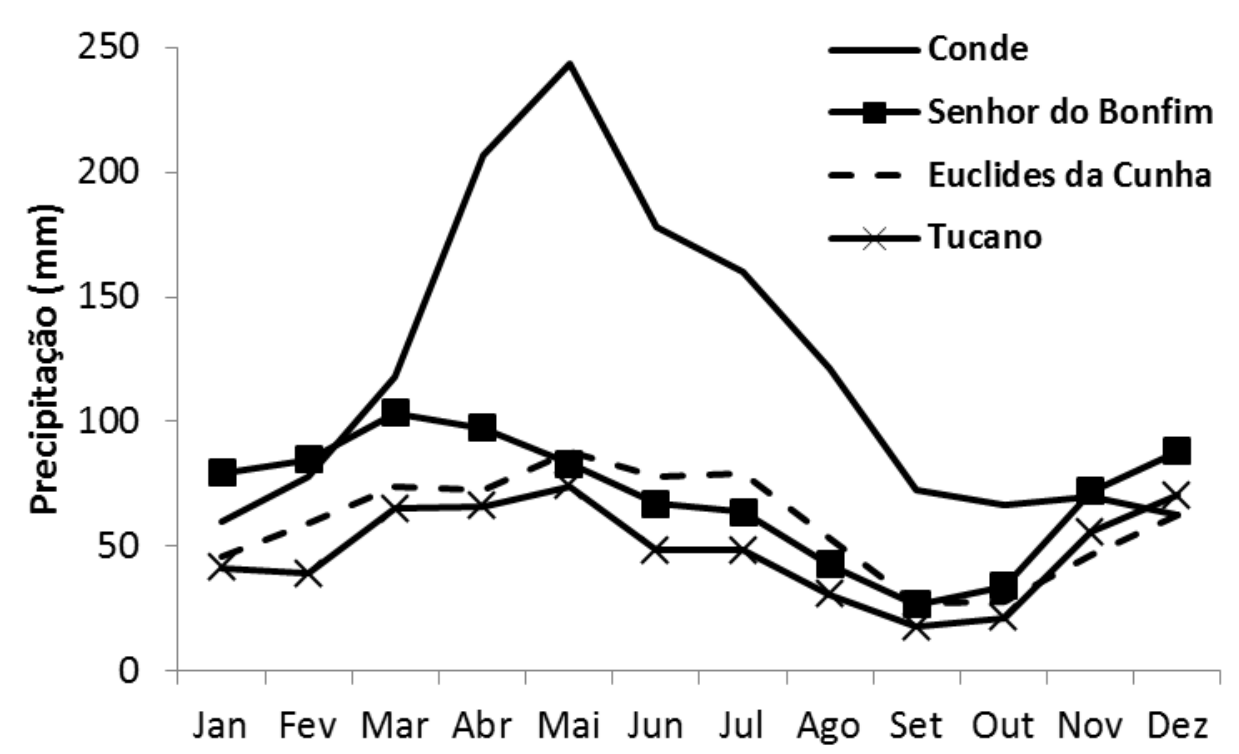

Figura 4 - Distribuição dos valores médios mensais da precipitação pluvial nos municípios de Senhor do Bonfim (alto curso), Euclides da Cunha e Tucano (médio curso) e Conde (baixo curso).

Observa-se ainda que a linha dos valores médios mensais nos municípios no médio curso da bacia hidrográfica (Euclides da Cunha e Tucano) seguem o mesmo padrão, com precipitações médias variando entre $25 \mathrm{~mm}$ até $100 \mathrm{~mm}$. No município pertencente ao alto curso (Senhor do Bonfim) teremos uma pequena diferença do padrão dos municípios no médio curso, com pluviosidade maior nos meses de fevereiro, março e abril, com valor médio de precipitação de $100 \mathrm{~mm}$. Já no tocante ao município do baixo curso (Conde) têm-se uma linha de distribuição de precipitação bastante diferenciada, com valor médio de precipitação significativo. A diferença nesses padrões é explicada pelos fatores geográficos diferenciados em cada um desses três trechos (baixo, médio e alto curso da bacia hidrográfica). 


\section{Conclusões}

Conclui-se que a distribuição da precipitação pluvial na bacia hidrográfica do Rio Itapicuru é condicionada por fatores geográficos, principalmente o relevo e a maritimidade. Os valores anuais mais elevados ocorrem no baixo curso, área litorânea, e na região de altitude mais acentuada. A região interplanáltica apresenta baixos valores de precipitação.

O conhecimento das características climáticas auxilia no planejamento ambiental e econômico do território, principalmente a variável precipitação, uma vez que, em regiões semiáridas, sua distribuição espacial e temporal é extremamente relevante.

\section{Bibliografia}

BRASIL. Ministério das Minas e energia. Secretaria - geral. Projeto RADAMBRASIL. Folhas SC.24/25 Aracaju/Recife; Geologia, geomorfologia, pedologia, vegetação e uso potencial da terra. Rio de janeiro, 1983.

MENDONÇA, F.; DANNI-OLIVEIRA, I. M. Climatologia: noções básicas e climas do Brasil. São Paulo: Oficina de Textos, 2007. 206 p.

MACHADO, L. A. T.; FERREIRA, N. J.; LAURENT, H. DIEDHIOU, A. Distúrbios Ondulatórios de Leste. e In.: CAVALANTI, I. F. de A.; FERREIRA, N. J.; SILVA, M. G. A. J.; DIAS, M. A. F. da S. (Orgs) Tempo e Clima no Brasil. São Paulo, Oficina de Textos, 2000.

MOLION, L. C. B.; BERNARDO, S. O. Uma revisão da dinâmica das chuvas no nordeste brasileiro. Revista Brasileira de Meteorologia, v.17, p. 1 - 10, 2002.

NOBRE, P.; SHUKLA, J. Variations of Sea Surface Temperature, Wind Stress, and Rainfall over the Tropical Atlantic and South America. Journal of Climate, v. 9, p. 2464 - 2479, 1996. 